\title{
Risks of lung cancer, chronic bronchitis, ischaemic heart disease, and stroke in relation to type of cigarette smoked
}

\author{
M R ALDERSON, * P N LEE, † AND R WANG \\ From the Institute of Cancer Research, Sutton, Surrey
}

SUMMARY In a case control study of over 12000 inpatients aged 35-74, risk of lung cancer, chronic bronchitis, and, particularly in those aged 35-54, ischaemic heart disease was positively associated with the number of manufactured cigarettes smoked daily and was negatively associated with long term giving up. Risk of stroke was not clearly related to smoking. Among manufactured cigarette smokers, lung cancer risk tended to be lowest in those who had always smoked filter cigarettes. This pattern was, however, evident only in men who additionally smoked pipes, cigars or handrolled cigarettes and in women, not being seen in men who smoked only manufactured cigarettes. Risk of lung cancer was not clearly related to time of switch to filter cigarettes. A markedly lower risk of chronic bronchitis was seen in men, but not women, who smoked filter rather than plain cigarettes. Heart disease risk did not vary by type of cigarette smoked 10 years before admission, but, compared with those who had never smoked filter cigarettes, those who had ever smoked filter cigarettes had a higher risk in men and a lower risk in younger women. Compared with the general population, markedly more controls were ex-smokers, suggesting incipient disease, whether or not smoking related, may alter smoking habits, thus affecting the interpretability of the findings. Control smokers were also relatively much more likely to report smoking plain cigarettes than expected. This comparison, not made in other studies relating risk to type of cigarette smoked, indicates that great care must be taken in verifying validity of reported smoking habits. While our findings are compatible with other evidence that risk of lung cancer and chronic bronchitis is probably reduced by switching from plain to filter cigarettes, they underline the difficulties in obtaining valid evidence from epidemiological studies.

In 1950 nearly all British smokers consumed untipped plain cigarettes with mean tar yields of over $30 \mathrm{mg}$. In 1976, when this study was planned, $88 \%$ of cigarettes smoked had filters, and mean tar yields had fallen to around $18 \mathrm{mg}$; these trends have continued subsequently. By 1976 , only four studies ${ }^{1-4}$ had compared risks of smoking associated diseases in smokers of high tar plain cigarettes and lower tar filter cigarettes. Only one study, by Dean et al, ${ }^{2}$ was carried out in the United Kingdom and it used a technique (comparison of smoking habits of decedents obtained second-hand from relatives with those of the living population obtained directly) which is open to criticism. The main aim of the present study was to relate type of cigarette smoked

"Present address: Office of Population Censuses and Surveys.

†'Present address: 25 Cedar Road, Sutton, Surrey SM2 5DG.

$\ddagger$ Present address: Department of Epidemiology, Tiensin Medical College, China. to prevalence of the same four index diagnoses-lung cancer (ICD 162), chronic bronchitis (ICD 491, 492, 496), ischaemic heart disease (ICD 410-414), and 'stroke' (ICD 431-438, excluding subarachnoid haemorrhage)-that Dean had studied. This paper reports the results found and compares them with those from both the earlier studies ${ }^{1-4}$ and seven more recent ones. ${ }^{5-11} \mathrm{~A}$ more extensive report is available on request from PNL.

\section{Methods and response}

The overall design was a case control study of hospital inpatients. For each index diagnosis, the intention was to interview 200 cases and 200 matched controls in each of the eight sex/age cells (ie, male or female, and aged $35-44,45-54,55-64$ or 65-74). This gave a target of 12800 patients, though 
for some categories (eg, young female chronic bronchitics) this would be unattainable. Patients were selected from medical (including chest medicine), thoracic surgery, and radiotherapy wards in hospitals with a large flow of such patients in major centres in 10 areas of the country. Interviewers visited the wards at regular intervals and selected cases based on provisional diagnosis. Controls were patients without one of the four index diseases, individually matched to cases on sex, age, hospital region, and, when possible, hospital ward and time of interview. The provisional diagnosis of the controls was not recorded; nor, at this stage, were controls with smoking associated diseases other than the four index diseases excluded.

Altogether 12693 interviews were achieved. The respondent was asked detailed questions on smoking, including brand smoked at admission and 1, 3, 5, and 10 years before admission, and number of cigarettes smoked at these times, at ages 16,20,25, and at the age when cigarette smoking was heaviest. Smoking habits at time of disease onset were not directly recorded as the time would have been difficult to identify, and this would have complicated analysis. The questions on brand allowed categorisation of tar, nicotine, and, for some years, carbon monoxide levels. A separate question on time of switching from smoking mainly plain to mainly filter cigarettes was included. Other aspects of smoking were also investigated as well as a whole range of possible confounding variables.

Final discharge diagnoses were subsequently abstracted from the hospital records for 11847 (93\%) of the patients interviewed by HAA clerks or by more senior records staff after the HAA record had been completed. These diagnoses were used to reallocate cases and controls as necessary. Patients without a final diagnosis kept their provisional diagnosis. Patients with multiple index diseases on final diagnosis were classified as lung cancer, if present, and, if not, to the index disease provisionally diagnosed. Overall $1966(17 \%)$ of the patients for whom final diagnoses were available changed their status, 1067 from case to control, 720 from control to case, and 179 from one type of case to another. Where changes had occurred, patients were regrouped into new case control pairs as appropriate.

With the assistance of Sir Richard Doll and $\mathrm{Mr}$ Richard Peto, non-index diagnoses were classified as follows:

class $1 A$ "definitely not smoking associated"

class $1 B$ "probably not smoking associated"

class $2 A$ "probably smoking associated"

class $2 B$ "definitely smoking associated"

Controls with no final diagnosis were considered class $1 \mathrm{~B}$. At the end of this procedure there were
4950 pairs with class 1 controls and 730 pairs with class 2 controls (table 1 ).

Interviewing started in the Newcastle locality in 1977 and in Leeds hospitals in 1978 and extended slowly to Manchester, Birmingham, Bristol, East Anglia, South Hampshire, Leicester, Nottingham, and Liverpool, ending in January 1982. Medical staff committees did not grant permission to interview in Oxford and Sheffield. Of $\mathbf{5 3}$ hospitals contacted in the 10 regions, seven declined to participate. Within the 46 hospitals, 11 clinicians approached did not wish their patients to be involved. Less than $1 \%$ of patients declined to be interviewed, while a few interviews were not completed for various reasons.

The statistical methods used generally followed classical methods for analysis of data from case control studies, ${ }^{12}$ cases and controls being separately tabulated by several levels of the risk factor of interest (ie, a $2 \times \mathrm{K}$ table), with potential confounding factors taken account of by stratification. Results presented are for combined strata and show the (Mantel-Haenszel) relative risk together with the significance of its difference from a base level (risk $1 \cdot 0)$ and/or of the dose related trend. Analysis was generally restricted to comparison of cases with their matched class 1 controls. Analysis also generally excluded the five pairs with ages outside the range initially specified (see table 1 ).

\section{Results}

VALIDITY OF THE DATA

Early on at each location patients were reinterviewed to check the quality of work of the interviewers and the reproducibility of the answers. These 508 second interviews were completed by a more senior

Table 1 Number of matched pairs after reallocation by class of control

\begin{tabular}{|c|c|c|c|c|c|c|}
\hline \multirow[b]{3}{*}{ Sex } & \multirow[b]{3}{*}{ Index disease } & \multicolumn{3}{|c|}{ Class 1 control } & \multirow{3}{*}{$\begin{array}{l}\text { Class } 2 \\
\text { control }\end{array}$} & \multirow{3}{*}{$\begin{array}{l}\text { Any } \\
\text { pair }\end{array}$} \\
\hline & & \multicolumn{2}{|c|}{ Age (yr) } & \multirow{2}{*}{$\begin{array}{l}\text { All* } \\
\text { ages }\end{array}$} & & \\
\hline & & $35-54$ & $55-74$ & & & \\
\hline \multirow[t]{2}{*}{ Male } & $\begin{array}{l}\text { Lung cancer } \\
\text { Chronic bronchitis } \\
\text { IHD } \\
\text { Stroke }\end{array}$ & $\begin{array}{l}375 \\
197 \\
412 \\
141\end{array}$ & $\begin{array}{l}443 \\
340 \\
399 \\
319\end{array}$ & $\begin{array}{l}819 \\
537 \\
811 \\
460\end{array}$ & $\begin{array}{l}206 \\
130 \\
139 \\
118\end{array}$ & $\begin{array}{r}1025 \\
667 \\
950 \\
578\end{array}$ \\
\hline & Totals & 1125 & 1501 & 2627 & 593 & 3220 \\
\hline \multirow[t]{2}{*}{ Female } & $\begin{array}{l}\text { Lung cancer } \\
\text { Chronic bronchitis } \\
\text { IHD } \\
\text { Stroke }\end{array}$ & $\begin{array}{l}204 \\
125 \\
309 \\
126\end{array}$ & $\begin{array}{l}426 \\
333 \\
402 \\
394\end{array}$ & $\begin{array}{l}630 \\
460 \\
712 \\
521\end{array}$ & $\begin{array}{l}46 \\
36 \\
21 \\
34\end{array}$ & $\begin{array}{l}676 \\
496 \\
733 \\
555\end{array}$ \\
\hline & Totals & 764 & 1555 & 2323 & 137 & 2460 \\
\hline
\end{tabular}

*One male and four female pairs outside age range 35-74. IHD=ischaemic heart disease. 
interviewer, usually within a few days of the first interview. No significant differences were found for questions having numerical answers. For most questions with qualitative answers, agreement was reached for well over $95 \%$ of patients. For the questions on reason for changing smoking habits and on brand smoked 10 years ago, discrepancies occurred in 3.5 to $5 \%$ of answers.

The final discharge diagnoses of 1002 patients were independently abstracted by MRA from the clinical records. Comparison with the diagnoses abstracted by the records staff showed no difference for $88 \%$, a minor difference for $10.6 \%$, and a major difference that would have affected allocation of the patients for $1.4 \%$.

All subjects who smoked manufactured cigarettes were asked whether these were filter or plain and, in a separate question, what the brand was. This allowed comparison of filter/plain status as directly asked and as indirectly assessed from the brand. The discrepancy between these two sources of information rose from $2-3 \%$ at the time of admission to $8-10 \%$ for smoking habits 10 years before admission. The proportion classified as plain smokers was, however, similar from the two sources.

Further validity checks were made by comparing smoking habits of class 1 controls with those seen in population surveys conducted for the Tobacco Research Council (TRC) ${ }^{13}$ (table 2). At admission, the hospital controls have a similar proportion who have never smoked, a considerably higher percentage of ex-smokers, and a lower percentage of current smokers of filter cigarettes and of other products (pipe, cigar, handrolled cigarettes). The increase in ex-smokers among hospital controls indicates an appreciable bias.

Among controls who smoked manufactured cigarettes, a markedly higher percentage reported

Table 2 Comparison of smoking habits reported by class 1 control patients and by respondents in Tobacco Research Council (TRC) surveys

\begin{tabular}{|c|c|c|c|c|c|}
\hline \multirow[b]{2}{*}{ Smoking habit } & \multirow[b]{2}{*}{ Time } & \multicolumn{2}{|l|}{ Males } & \multicolumn{2}{|c|}{ Females } \\
\hline & & $T R C$ & Controls & $T R C$ & Controls \\
\hline \multicolumn{6}{|c|}{ Percentage of total population * } \\
\hline Never smoked & At admission & $18 \cdot 2$ & $15 \cdot 5$ & $44 \cdot 4$ & $43 \cdot 2$ \\
\hline Ex-smokers & At admission & $26 \cdot 9$ & $40 \cdot 1$ & $17 \cdot 9$ & $28 \cdot 1$ \\
\hline $\begin{array}{l}\text { Smoker-not man. cigs. } \\
\text { Manufactured cigarettes }\end{array}$ & At admission & $17 \cdot 6$ & $11 \cdot 8$ & $0 \cdot 8$ & $0 \cdot 4$ \\
\hline Plain & At admission & $5 \cdot 7$ & $7 \cdot 8$ & $1 \cdot 9$ & $3 \cdot 2$ \\
\hline Filter & At admission & $31 \cdot 5$ & $24 \cdot 9$ & $35 \cdot 0$ & $25 \cdot 1$ \\
\hline \multicolumn{6}{|c|}{ Percentage of all manufactured cigarettes smokerst } \\
\hline Plain & 1979 & $17 \cdot 6$ & $25 \cdot 6$ & $4 \cdot 8$ & $12 \cdot 3$ \\
\hline Plain & 1976 & $22 \cdot 3$ & $30 \cdot 9$ & $7 \cdot 2$ & $15 \cdot 0$ \\
\hline Plain & 1974 & $29 \cdot 2$ & $35 \cdot 6$ & $10 \cdot 4$ & $19 \cdot 0$ \\
\hline Plain & 1969 & $36 \cdot 0$ & $48 \cdot 0$ & $17 \cdot 2$ & 26.5 \\
\hline
\end{tabular}

*Standardised for age and year of admission.

+Standardised for age and region. smoking plain cigarettes than expected from TRC national survey data. This was evident not only at admission, but also in earlier years (table 2). Over the whole period the odds of a class 1 control being a plain smoker relative to the TRC national data averages around 1.5 for males and 2.2 for females. This bias is large compared with the estimates of plain/filter relative risk reported in other studies.

\section{"COMPENSATION"}

Smokers who switch to cigarettes with reduced tar and nicotine might in theory "compensate" by increasing numbers of cigarettes smoked or by altering the way they smoked. No evidence of increased consumption was seen in analyses comparing smokers who had or had not decreased the nicotine yield of the brand they smoked between 10 and 5 years before admission. It was not possible to evaluate the second form of compensation.

RELATIVE RISK IN RELATION TO SMOKING Table 3 presents risks by lifetime history of smoking. In both sexes cigarette smoking was highly significantly associated with lung cancer, chronic bronchitis, and, in the 35-54 age group, ischaemic heart disease. It was not significantly associated with ischaemic heart disease in older subjects or with stroke. Risks of lung cancer and chronic bronchitis were higher, though not significantly, in handrolled than in manufactured cigarette smokers. In the absence of cigarettes, pipe and/or cigar smoking was associated with an increased risk of lung cancer but not of other diseases. Additional analysis showed smoking to be more strongly associated with squamous and small cell lung cancer than with other types of lung cancer.

In table 3, comparisons are based on final diagnosis. Comparison was also made of those whose diagnosis had or had not changed from that provisionally assigned. While some differences in smoking habits were seen, in particular a tendency for control patients originally interviewed as cases to be more often smokers than those originally interviewed as controls, the extent of any potential bias seemed slight (see full report for details).

In both sexes, number of manufactured cigarettes smoked per day at time of heaviest smoking was significantly related to lung cancer, chronic bronchitis, and, in those aged 35-54, ischaemic heart disease. In females, a dose-relation was also seen for ischaemic heart disease in the older age group.

Table 4 presents risks by time manufactured cigarettes were last smoked. Compared with those still smoking at admission, risk of lung cancer was significantly increased among those last smoking one or three years before, presumably because many 
Table 3 Relative risk $(R)$ of index diseases compared with those who have never smoked by lifetime history of smoking (standardised for age) together with number of cases (N1) and controls (N2)

\begin{tabular}{|c|c|c|c|c|c|c|c|}
\hline \multirow[b]{2}{*}{ Sex } & \multirow[b]{2}{*}{ Lifetime history of smoking } & & \multicolumn{5}{|l|}{ Index diseases } \\
\hline & & & $\begin{array}{l}\text { Lung } \\
\text { cancer }\end{array}$ & $\begin{array}{l}\text { Chronic } \\
\text { bronchitis }\end{array}$ & $\begin{array}{l}I H D \\
35-54\end{array}$ & $\begin{array}{l}I H D \\
55-74\end{array}$ & Stroke \\
\hline Male & $\begin{array}{l}\text { Never smoked } \\
\text { Pipe and/or cigars, no cigarettes } \\
\text { Pipe and/or cigars and cigarettes } \\
\text { Handrolled cigarettes only } \\
\text { Handrolled and manufactured cigarettes } \\
\text { Manufactured cigarettes only }\end{array}$ & $\begin{array}{l}\text { R } \\
\text { N1 } \\
\text { N2 } \\
\text { R } \\
\text { N1 } \\
\text { N2 } \\
\text { R } \\
\text { N1 } \\
\text { N2 } \\
\text { R } \\
\text { N1 } \\
\text { N2 } \\
\text { R } \\
\text { N1 } \\
\text { N2 } \\
\text { R } \\
\text { N1 } \\
\text { N2 }\end{array}$ & $\begin{array}{l}1 \cdot 00 \\
15 \\
133 \\
3 \cdot 82++ \\
17 \\
35 \\
9 \cdot 09+++ \\
206 \\
179 \\
18 \cdot 05+++ \\
32 \\
13 \\
12 \cdot 87+++ \\
159 \\
100 \\
9 \cdot 27+++ \\
385 \\
349\end{array}$ & $\begin{array}{l}1 \cdot 00 \\
25 \\
63 \\
1 \cdot 20 \\
8 \\
19 \\
2 \cdot 56++ \\
113 \\
132 \\
5 \cdot 74+++ \\
21 \\
9 \\
3 \cdot 23+++ \\
92 \\
66 \\
2 \cdot 82+++ \\
276 \\
243\end{array}$ & $\begin{array}{l}1 \cdot 00 \\
46 \\
77 \\
0 \cdot 73 \\
4 \\
9 \\
2 \cdot 42+++ \\
122 \\
85 \\
2 \cdot 56 \\
12 \\
10 \\
2 \cdot 42++ \\
58 \\
48 \\
1 \cdot 63+ \\
161 \\
178\end{array}$ & $\begin{array}{c}1 \cdot 00 \\
51 \\
49 \\
0 \cdot 83 \\
21 \\
23 \\
0 \cdot 83 \\
112 \\
120 \\
1 \cdot 00 \\
6 \\
5 \\
1 \cdot 30 \\
31 \\
22 \\
0 \cdot 91 \\
168 \\
175\end{array}$ & $\begin{array}{c}1 \cdot 00 \\
60 \\
68 \\
1 \cdot 13 \\
23 \\
23 \\
1 \cdot 48 \\
112 \\
84 \\
1 \cdot 03 \\
12 \\
13 \\
1 \cdot 06 \\
48 \\
50 \\
1 \cdot 05 \\
201 \\
220\end{array}$ \\
\hline Female & Manufactured cigarettes only & $\begin{array}{l}\text { R } \\
\text { N1 } \\
\text { N2 } \\
\text { R } \\
\text { N1 } \\
\text { N2 }\end{array}$ & $\begin{array}{l}1 \cdot 00 \\
75 \\
243 \\
4 \cdot 75+++ \\
530 \\
371\end{array}$ & $\begin{array}{l}1 \cdot 00 \\
105 \\
203 \\
2 \cdot 79+++ \\
333 \\
239\end{array}$ & $\begin{array}{l}1 \cdot 00 \\
69 \\
119 \\
2 \cdot 13+++ \\
231 \\
184\end{array}$ & $\begin{array}{l}1 \cdot 00 \\
156 \\
181 \\
1 \cdot 30 \\
232 \\
208\end{array}$ & $\begin{array}{l}1 \cdot 00 \\
231 \\
239 \\
1 \cdot 10 \\
272 \\
267\end{array}$ \\
\hline
\end{tabular}

NB Women who have ever smoked pipes, cigars or handrolled cigarettes excluded. Controls are class 1.

$+++p<0.001 ; \quad++p<0.01 ; \quad+p<0.05 ;$ compared with never smoked.

Table 4 Relative risk $(R)$ of index diseases by time last smoked manufactured cigarettes (standardised for age)

\begin{tabular}{|c|c|c|c|c|c|c|}
\hline \multirow[b]{2}{*}{ Sex } & \multirow[b]{2}{*}{ Time last smoked manufactured cigarettes } & & \multicolumn{4}{|l|}{ Index diseases } \\
\hline & & & $\begin{array}{l}\text { Lung } \\
\text { cancer }\end{array}$ & $\begin{array}{l}\text { Chronic } \\
\text { bronchitis }\end{array}$ & $\begin{array}{l}I H D \\
35-54\end{array}$ & $\begin{array}{l}I H D \\
55-74\end{array}$ \\
\hline Male & $\begin{array}{l}\text { At admission } \\
1 \text { or } 3 \text { years before } \\
5 \text { or } 10 \text { years before } \\
\text { Earlier } \\
\text { Never smoked }\end{array}$ & $\begin{array}{l}\mathbf{R} \\
\mathbf{R} \\
\mathbf{R} \\
\mathbf{R} \\
\mathbf{R}\end{array}$ & $\begin{array}{l}1 \cdot 00 \\
1 \cdot 81++ \\
0 \cdot 43-- \\
0 \cdot 32--- \\
0 \cdot 10---\end{array}$ & $\begin{array}{l}1.00 \\
1.05 \\
0.89 \\
0.65 \\
0.33---\end{array}$ & $\begin{array}{l}1.00 \\
1.27 \\
0.68 \\
0.50 \\
0.56\end{array}$ & $\begin{array}{l}1 \cdot 00 \\
1 \cdot 80 \\
1 \cdot 14 \\
1 \cdot 55 \\
1 \cdot 37\end{array}$ \\
\hline Female & $\begin{array}{l}\text { At admission } \\
1 \text { or } 3 \text { years before } \\
5 \text { or } 10 \text { years before } \\
\text { Earlier } \\
\text { Never smoked }\end{array}$ & $\begin{array}{l}\mathbf{R} \\
\mathbf{R} \\
\mathbf{R} \\
\mathbf{R} \\
\mathbf{R}\end{array}$ & $\begin{array}{l}1 \cdot 00 \\
2 \cdot 08+++ \\
0 \cdot 65 \\
0 \cdot 28--- \\
0 \cdot 22---\end{array}$ & $\begin{array}{l}1 \cdot 00 \\
0.85 \\
1 \cdot 01 \\
0.51- \\
0.29---\end{array}$ & $\begin{array}{l}1.00 \\
0.84 \\
0.56 \\
(0.41) \\
0.41---\end{array}$ & $\begin{array}{l}1.00 \\
0.73 \\
0.74 \\
0.55- \\
0.60--\end{array}$ \\
\hline
\end{tabular}

NB Subjects who have ever smoked pipes, cigars or handrolled cigarettes excluded. Bracketed figure based on less than 10 cases.

,$+++---p<0.001 ;++,--p<0.01 ;+,-p<0.05 ;$ compared with at admission.

smokers with lung cancer gave up smoking shortly before admission. Risk was significantly decreased among long-term ex-smokers. A similar pattern seemed to be true for chronic bronchitis, except that here sufferers may have given up smoking because of the disease many years before admission. The evidence regarding heart disease is less clear, though long-term ex-smokers and never smokers had similar risks in all analyses. Here, and subsequently, results for stroke are not presented as no clear associations with any aspect of smoking were seen.

Table 5 compares risk in smokers of filter and plain cigarettes. Standardisation takes account of possible confounding by number smoked. The tendency for smokers to change their habits because of disease is taken account of by ignoring recent changes in smoking, comparisons being based on lifetime habits up to three years before admission. In an additional analysis, not shown in detail here, comparisons were made based on filter/plain status at specific time points, 3,5 or 10 years before admission.

In males, lung cancer was not significantly related to type of cigarette smoked. In females, some reduction in risk was seen in those who had never smoked plain cigarettes, but no trend was evident in relation to length of use of filter cigarettes. Nor did 
Table 5 Relative risk $(R)$ ofindex diseases by lifetime filter/plain smoking habits for those smoking manufactured cigarettes 3 years before admission regardless of whether they subsequently gave up (standardised for age and number of cigarettes smoked 3 years before admission) together with number of cases (N1) and controls (N2)

\begin{tabular}{|c|c|c|c|c|c|c|}
\hline \multirow[b]{2}{*}{ Sex } & \multirow[b]{2}{*}{ Lifetime filter/plain smoking habits* } & & \multicolumn{4}{|c|}{ Index diseases } \\
\hline & & & $\begin{array}{l}\text { Lung } \\
\text { cancer }\end{array}$ & $\begin{array}{l}\text { Chronic } \\
\text { bronchitis }\end{array}$ & $\begin{array}{l}I H D \\
35-54\end{array}$ & $\begin{array}{c}I H D \\
55-74\end{array}$ \\
\hline Male & $\begin{array}{l}\text { Switched to filter up to } 10 \text { years before } \\
\text { admission } \\
\text { Switched to filter more than } 10 \text { years } \\
\text { before admission } \\
\text { Always filter } \\
\text { Ever filter/never filter } \\
\text { Never plain/ever plain }\end{array}$ & $\begin{array}{l}\text { R } \\
\text { N1 } \\
\text { N2 } \\
\text { R } \\
\text { N1 } \\
\text { N2 } \\
\text { R } \\
\text { N1 } \\
\text { N2 } \\
R \\
\text { N1 } \\
\text { N2 } \\
\text { R } \\
\text { R }\end{array}$ & $\begin{array}{c}1.00 \\
105 \\
73 \\
1 \cdot 13 \\
47 \\
28 \\
1.09 \\
125 \\
88 \\
1.48 \\
35 \\
24 \\
1.20 \\
1.48\end{array}$ & $\begin{array}{l}1 \cdot 00 \\
70 \\
36 \\
0.80 \\
36 \\
22 \\
0.43-- \\
49 \\
64 \\
0.25-- \\
8 \\
16 \\
0.50-- \\
0.45\end{array}$ & $\begin{array}{l}1.00 \\
22 \\
33 \\
2.96+ \\
21 \\
10 \\
1.69 \\
65 \\
57 \\
1.78 \\
19 \\
19 \\
1.83 \\
1.05\end{array}$ & $\begin{array}{l}1.00 \\
23 \\
42 \\
2.02 \\
16 \\
14 \\
1.68 \\
42 \\
44 \\
2.67 \\
11 \\
7 \\
1.90 \\
1.85\end{array}$ \\
\hline Female & $\begin{array}{l}\text { Always plain } \\
\begin{array}{l}\text { Switched to filter up to } 10 \text { years before } \\
\text { admission }\end{array} \\
\text { Switched to filter more than } 10 \text { years } \\
\text { before admission } \\
\text { Always filter }\end{array}$ & $\begin{array}{l}\text { R } \\
\text { N1 } \\
\text { N2 } \\
\text { R } \\
\text { N1 } \\
\text { N2 } \\
\text { R } \\
\text { N1 } \\
\text { N2 } \\
\text { R } \\
\text { N1 } \\
\text { N2 } \\
\text { R } \\
\text { R }\end{array}$ & $\begin{array}{c}1.00 \\
62 \\
37 \\
1.04 \\
44 \\
23 \\
1.41 \\
170 \\
69 \\
0.85 \\
134 \\
100 \\
1.09 \\
0.66-\end{array}$ & $\begin{array}{l}1 \cdot 00 \\
33 \\
23 \\
1 \cdot 47 \\
30 \\
14 \\
1 \cdot 16 \\
83 \\
40 \\
0 \cdot 75 \\
61 \\
63 \\
1 \cdot 04 \\
0.64\end{array}$ & $\begin{array}{l}1 \cdot 00 \\
23 \\
4 \\
0 \cdot 18- \\
17 \\
23 \\
0 \cdot 39 \\
85 \\
54 \\
0 \cdot 24- \\
73 \\
61 \\
0.27- \\
0.77\end{array}$ & $\begin{array}{l}1 \cdot 00 \\
21 \\
21 \\
1 \cdot 02 \\
22 \\
14 \\
1 \cdot 55 \\
52 \\
36 \\
1 \cdot 32 \\
51 \\
43 \\
1.41 \\
0.98\end{array}$ \\
\hline
\end{tabular}

* Smoking habits less than 3 years before admission in which interview occurred ignored so that always plain and never filter include some subjects who switched to filter in this period.

NB Subjects who have ever smoked pipes, cigars or handrolled cigarettes excluded.

,$+++--p<0.001 ;++,--p<0.01 ;+,-p<0.05$.

female lung cancer risk vary by filter/plain status at any given time point.

In males, there was a clear reducing trend in chronic bronchitis risk by time of switch. In females, no significant differences were seen though, as for lung cancer, those who had never smoked plain cigarettes had the lowest risk.

The results for ischaemic heart disease showed evidence of conflicting patterns with an advantage to filter cigarette smokers for females and a disadvantage for males. However, no filter/plain differences were seen in either sex when subjects were classified according to smoking habits 10 years before admission.

In an attempt to exclude patients who had altered their smoking habits because of onset of symptoms, analyses were carried out for lung cancer on patients who had not been previously hospitalised and who did not have symptoms of chronic bronchitis. This markedly reduced the number of patients available. The general relation of increased risk to heavy smoking was evident, but no significant reduction in risk in smokers of filter cigarettes was seen.

In table 5, patients who had ever smoked products other than manufactured cigarettes were excluded. In additional analyses, smokers of manufactured cigarettes and other products who had ever smoked filter cigarettes had less than half the risk of lung cancer of those who had never smoked filter cigarettes $(R=0.45, p<0.01)$. Analyses of all manufactured cigarette smokers and of only those who also smoked other products were also carried out for men for the other diseases, but conclusions were unaffected.

Subjects were categorised by the tar level of the brand of cigarettes smoked 10 years before admission. Though the lowest tar group generally had the lowest risk, the differences within any diagnosis were not marked or very consistent between the sexes, the only analysis showing a significant $(p<0.05)$ trend being for chronic bronchitis in males, where the risk was almost twice 
as high in smokers of brands with tar yields of $29+\mathrm{mg}$ as in smokers of brands with tar yields of $17-22 \mathrm{mg}$.

For lung cancer and ischaemic heart disease, change in number of cigarettes smoked was not related to risk. Risk of chronic bronchitis was higher in those who had recently reduced the number of cigarettes smoked.

No clear relation of inhalation, relighting, tar/nicotine ratio, holding the cigarette in the mouth or butt length to risk of the index diseases was seen; nor were conclusions affected by taking into account any of the wide range of potential confounding variables studied. Details of these and many other analyses carried out are given in the full report.

\section{Discussion}

Before attempting to interpret the results, one must consider the validity of the data collected and the possibility of faults in the study design. Considering validity first, it seems from such independent checks as are possible that the data are of the level of accuracy usually obtained in large epidemiological studies. That control patients originally interviewed as cases were somewhat more likely to be smokers than those originally interviewed as controls is consistent with some degree of bias due to patients or interviewers being aware of the diagnosis but may be due to knowledge of smoking habits affecting preliminary diagnosis. More serious are doubts about the validity of the smoking history data; about $10 \%$ of the subjects said that they smoked a brand 10 years before admission that was inconsistent with answers to a previous question on the time of switch from plain to filter cigarettes.

It is clear that our control patients, even though not suffering from smoking related diseases, contained relatively more ex-smokers than expected from the general population. Also, the proportion of cigarette smokers reporting smoking plain cigarettes was higher than is seen nationally, not only at admission, but also for the whole 10 years before admission. Whether the factors leading to this discrepancy have also applied to cases is not clear, and this creates difficulty in interpreting the results of the analyses of switching to filter cigarettes. It is not, however, self-evident that comparison with population controls would automatically produce the correct results. This query over the ratio of plain to filter cigarette smokers among the controls has an important bearing on the interpretation of the results for which there is no known correction.

In theory, those who switch to cigarettes with reduced tar and nicotine may "compensate" by either increasing the number of cigarettes smoked daily or by altering the manner of smoking. A number of studies have indicated that compensation by increasing cigarette consumption is, at most, only minimal, ${ }^{14}$ and our failure to find any evidence of such an effect confirms this impression. In the present study, it was not possible to check whether the way of smoking had altered intake of tar or nicotine.

Another problem in relating risk to type of cigarette smoked is that there is no time when there are substantial numbers of both smokers of the old high tar plain cigarettes and of smokers of the reduced tar filter cigarettes.

A final problem general to case control studies lies in doubts about their ability to detect other than substantial differences in risk. The method has recently been the subject of considerable criticism. ${ }^{15}$ Biases in many such studies may distort the relative risks recorded, while small numbers and errors in the data can reduce the power to detect a real effect. As a rule-of-thumb it is suggested that a well designed case control study should be able to confirm a twofold difference in risk but that, for differences less than this, the power of the study design may be inadequate.

As many have found, the risk of lung cancer, chronic bronchitis, and, particularly in those aged 35-54, ischaemic heart disease was positively associated with the number of manufactured cigarettes smoked daily and was negatively associated with long-term giving up. A number of pieces of evidence suggested that those with an increasing burden of disease are likely to give up smoking or reduce the number of cigarettes they smoke. These include the increased risk in recent ex-smokers of lung cancer (in both sexes) and of ischaemic heart disease (in males), the lack of dependence of risk of chronic bronchitis on whether or not a smoker gave up smoking up to 10 years before admission, and the tendency for risk of chronic bronchitis to be higher for those who reduce the number of cigarettes they smoke than for those who do not.

A review ${ }^{16}$ of the effect of type of cigarette on risk of disease emphasised the consistency of the results, despite the diverse nature of the reported studies, noting that generally smokers of filter (or lower tar-nicotine) cigarettes have a lower mortality than smokers of plain (or higher tar-nicotine) cigarettes for those diseases most strongly associated with smoking, and a slightly reduced mortality for those diseases less associated with smoking. It is of interest to compare and contrast findings from the present study and from other studies for each of the four index diagnoses in turn.

For lung cancer, findings from 11 studies ${ }^{1-5} 7-1117$ provide 20 separate results. Nineteen show a reduced 
risk in filter or lower tar cigarette smokers, the weighted average relative risk being 0.71 for males and 0.60 for females. In the current study, no evidence of a reduction in risk in relation to filters was seen in male smokers of manufactured cigarettes only, but some evidence of a reduction in risk was seen for those who had never smoked plain cigarettes compared with those who had ever smoked plain cigarettes $(a)$ in females (relative risk $=0.68$ ) and $(b)$ among males who also smoked other products (relative risk $=0 \cdot 57$ ). For females, however, because the highest risks were seen, not in lifetime plain cigarette smokers but in smokers who had switched from plain to filter over 10 years before admission, other comparisons of risk in filter and plain smokers did not show any advantage to filters.

In comparing our results with those of other studies, a number of points have to be considered. Firstly, some variation is to be expected due to sampling error with $95 \%$ confidence limits of the relative risk for most comparisons at least $\pm 30 \%$. Secondly, there is the question of how to take into account the smoking of products other than manufactured cigarettes. As we did, Dean ${ }^{2}$ excluded such smokers to avoid problems of adequate standardisation particularly of number of handrolled cigarettes and to give a "cleaner" sample, but many studies have included such smokers. Thirdly, we have shown that the ratio of plain to filter cigarette smokers is much higher in the hospital controls than is seen nationally; it is unreasonable to assume that this is a problem specific to our study, but other studies do not appear to have carried out this check. For example, Lubin ${ }^{7}$ presented tables demonstrating that a substantial proportion of "lifetime filter smokers" had smoked filter cigarettes for over 40 years, no comment being made that sales of filter cigarettes were extremely low even 30 years ago. ${ }^{14}$

Such data as are available for chronic bronchitis or emphysema from other studies all show an advantage to filters or reduced tar-nicotine (T-N). Thus Dean ${ }^{2}$ found significantly reduced risks in filter cigarette smokers in both men and women while Hammond ${ }^{16}$ found non-significantly reduced risks, compared with high T-N smokers, in both medium and low T-N smokers. The clear reduction seen in our study in filter cigarette smokers in males, coupled with the somewhat lower risks seen in females who have never smoked plain cigarettes, seem not inconsistent with this evidence. However, it should be remembered that analysis of the effect of type of cigarette on chronic bronchitis is particularly difficult, especially in case control studies, because of the undoubted tendency for sufferers to change their smoking habits because of the disease.
Six studies for ischaemic heart disease 23561718 provide 11 sets of comparisons. Although three show some apparent adverse effect of the switch to filters or reduced nicotine cigarettes, none is statistically significant. Indeed, apart from the large Hammond study, where significant reductions in risk of $10-20 \%$ were seen in three of the four analyses, all other results have quite wide confidence limits and are consistent with the weighted average relative risk of $\mathbf{0 . 9 6}$ for males and $\mathbf{0 . 8 5}$ for females for all the studies combined. Our results, if reported smoking habits $\mathbf{1 0}$ years before admission are considered, are also not inconsistent with this weighted average. However, if one considers analyses based on smoking habits closer to admission, the patterns are much less clear and are conflicting for the two sexes. Thus, compared with smokers who always smoke plain cigarettes, those switching to filters in the 10 years before admission show a risk of ischaemic heart disease that is significantly increased in men, significantly decreased in women aged 35-54, and unchanged in women aged 55-74. An explanation for these conflicting patterns is not easy but may lie partly in 0 the effect of incipient disease on smoking habits and partly in the inaccuracy of statements regarding smoking habits.

Whether smoking itself is related to the incidence of stroke is not established. Both Dean ${ }^{2}$ and Hammond ${ }^{16}$ show lower risks in filter or reduced $\mathrm{T}-\mathrm{N}$ smokers, though only in one analysis (Hammond: male: low $v$ high $\mathrm{T}-\mathrm{N}$ ) was the reduction statistically significant. Our own study found no significant relation of either lifetime smoking history or type of cigarette smoked to stroke.

Our results do not show, for any of the four diseases, an advantage to filter cigarettes that is clearly evident in both sexes. However, they are compatible with the general impression from other studies that switching to filter cigarettes is likely to show a benefit for lung cancer and for chronic bronchitis. In trying to find reasons for the unclear result, a number of points should be made. (1) There is clear evidence of a bias from patients with incipient disease (whatever the cause) altering their smoking habits. (2) Smokers are now more inclined to accept that smoking entails risks of respiratory disease and heart disease than hitherto. ${ }^{19}$ This may have affected the validity of the responses to the questions on smoking. (3) Filter and plain cigarettes differ from country to country, and from time to time with consequent variation in relative risk. (4) Those who initially switched to filter cigarettes may have been individuals who obtained a lower intake per cigarette by virtue of the way they smoked (thus being at lower risk of disease independently of their switch to filter 
cigarettes). (5) Individuals switching to filter cigarettes may "compensate" to some extent for the reduced deliveries of smoke constituents by adjusting the way in which they smoke. ${ }^{14}$ These five points taken together may help to explain differences between our results and those seen in other studies, though one cannot quantify their relative importance.

Those concerned to reduce the burden of disease from smoking will wish to consider the present results. The data confirm that never smoking is the ideal, with starting smoking "late", keeping the maximum number of cigarettes down to a low level, and stopping smoking "early" all associated with a reduced risk. The results also indicate, in line with those of other studies, that, at least for lung cancer and chronic bronchitis, switching to filter cigarettes may be associated with lower risks of these diseases. Our findings, especially for lung cancer, are not particularly clear, and the study highlights a number of difficulties in obtaining valid estimates of the effects of changing the type of cigarette smoked. More research is needed. This is in agreement with a recent statement that evaluation of the health effects of low yield cigarettes will remain a challenge to experimentalists and epidemiologists for many years to come. ${ }^{20}$

This study was funded by the Tobacco Research Council (now Tobacco Advisory Council), to whom we are most grateful. Dr Wang held a British Council award for the period 1980-83.

Mr I Marks from Research Surveys of Great Britain provided advice in the planning phase and was responsible for the interviewers' vital contribution to the study. We thank the many clinicians at the 46 participating hospitals who permitted us to contact their patients, and the twelve thousand who answered the questions.

Sir Richard Doll and Mr Richard Peto advised on the conditions that should be considered smoking related. A number of colleagues have commented on ways of handling the biases from health-related changes in smoking behaviour.

Data on tar, nicotine, and $\mathrm{CO}$ yields of brands were provided by the Tobacco Advisory Council and by Professor Nicholas Wald, when not available in published statistics.

Any views expressed in this paper are those of the authors and not of any other person or company.
Reprint requests to: P N Lee, 25 Cedar Road, Sutton, Surrey SM2 5DG.

\section{References}

${ }^{1}$ Bross IDJ, Gibson R. Risks of lung cancer in smokers who switch to filter cigarettes. Am J Publ Hlth 1968; 58: 1396-1403.

${ }^{2}$ Dean G, Lee PN, Todd GF, Wicken AJ. Report on a second retrospective mortality study in North East England, part 1. Tobacco Research Council, 1977.

${ }^{3}$ Hammond EC, Garfinkel L, Seidman H, Lew EA. Tar and nicotine content of cigarette smoke in relation to death rates. Environ Res 1976; 12: 263-74.

${ }^{4}$ Wynder EL, Mabuchi K, Beattie EJ. The epidemiology of lung cancer; recent trends. J Am Med Ass 1970; 213: 2221-8.

${ }^{5}$ Hawthorne VM, Fry JS. Smoking and health: cardiorespiratory disease, mortality, and smoking behaviour in West Central Scotland. J Epidemiol Community Health 1978; 32: 260-6.

${ }^{6}$ Kaufman DW, Helmrich SP, Rosenberg L, Miettinen OS, Shapiro S. Nicotine and carbon monoxide content of cigarette smoke and the risk of myocardial infarction in young men. New Engl J Med 1983; 308: 409-13.

${ }^{7}$ Lubin JH, Blot WJ, Berrino F, et al. Patterns of lung cancer risk according to type of cigarette smoked. Int J Cancer 1984; 33: 569-76.

${ }^{8}$ Rimington J. The effect of filters on the incidence of lung cancer in cigarette smokers. Environ Res 1981; 24: $162-6$.

${ }^{9}$ Vutuc C, Kunze M. Lung cancer risk in women in relation to tar yields of cigarettes. Prev Med 1982; 11: 713-6.

${ }^{10}$ Vutuc $\mathrm{C}$, Kunze $\mathrm{M}$. Tar yields of cigarettes and male lung cancer risk. J Natl Cancer Inst 1983; 71: 435-7.

${ }^{11}$ Wynder EL, Stellman SD. The impact of long-term filter cigarette usage in lung and larynx cancer risk: a case-control study. J Natl Cancer Inst 1979; 62: 471-7.

12 Breslow NE, Day NE. Statistical methods in cancer research Vol 1-The analysis of case-control studies. Lyon: International Agency for Research in Cancer, 1980.

${ }^{13}$ Lee PN. Statistics of smoking in the United Kingdom. TRC Research Paper No. 1, 7 edn Tobacco Research Council, London 1976 together with annual supplements and special tabulations supplied by Research Services.

${ }^{14}$ Lee PN. Lung cancer and type of cigarette smoked. In: Mizell $\mathbf{M}$, Correa $\mathbf{P}$, eds. Lung cancer: causes and prevention. Deerfield Beach: Verlag Chemie International, $1984 ; 273-84$.

${ }^{15}$ Alderson MR. An introduction to epidemiology 2nd edn. London: Macmillan, 1983.

${ }^{16}$ Lee PN, Garfinkel L. Mortality and type of cigarette smoked. J Epidemiol Community Health 1981; 35: 16-22.

${ }^{17}$ Rose GA. Unpublished findings quoted by Lee and Garfinkel, 1981-reference 16.

${ }^{18}$ Castelli WP, Garrison RJ, Dawber TR, McNamara PM, Feinlieb M, Kannell WM. The filter cigarette and coronary heart disease: The Framingham Study. Lancet 1981; ii: 109-13.

${ }^{19}$ Marsh A, Matheson J. Smoking attitudes and behaviour. London: HMSO, 1983.

${ }^{20}$ Wynder EL, Goodman MT. Smoking and lung cancer; some unresolved issues. Epidemiol Rev 1983; 5: 177-207. 